\title{
Implementasi Rekam Medis Elektronik dengan Sistem Pendukung Keputusan Klinis
}

\author{
Feby Erawantini \\ Jurusan Kesehatan \\ Politeknik Negeri Jember \\ Jember, Indonesia \\ feby_erawantini@polije.ac.id
}

\author{
Nugroho Setyo Wibowo \\ Jurusan Teknologi Informasi \\ Politeknik Negeri Jember \\ Jember, Indonesia \\ nugroho@polije.ac.id
}

\begin{abstract}
- the community has the right to get quality and affordable health services. One effort to realize quality health services is the electronic medical record. The RME application is expected to be integrated between health services and has a function as a clinical decision support system the existing medical record are still in the form of paper medical records, so that they are easly lost, damaged, and they do not support to clinical decission making. The development RME is still limited to the interest payment, and patiens registration. $R M E$ is included CDSS and prediction of diagnosis has never existed especially in Indonesia. The purpose of this study is to implement the RME application in the educational clinic and evaluate the user's satisfaction about the RME application has been implemented. The method used for RME implementation was parallel implementation and evaluation of user satisfaction by the end user computing satisfaction method. Implementation of the RME application was carried out for 2 months in the educational clinic, from September to October 2019. The study involved 2 doctors, 1 registration officer, 2 nurses and 1 pharmacy officer. The results of RME application research can be implemented in educational clinic, RME applications with clinical decision support system in the form of blood pressure, risk of Diabetes Mellitus, risk of stroke, interaction of drug content with a history of allergies, as well as abnormal warnings of laboratory and radiological examination results.
\end{abstract}

Keywords-implementation; Aplication; Electronic Medical Record; Educational Clinic.

\footnotetext{
Abstrak - Masyarakat memiliki hak untuk mendapatkan pelayanan kesehatan yang bermutu dan terjangkau. Salah satu upaya untuk mewujudkan pelayanan kesehatan yang bermutu yaitu rekam medis elektronik. Aplikasi RME diharapkan terintegrasi antar pelayanan kesehatan dan mempunyai fungsi sebagai pendukung keputusan klinis. Rekam medis yang ada saat ini masih berupa rekam medis kertas sehingga mudah hilang, rusak dan tidak mendukung pengambilan keputusan klinis. Pengembangan RME masih sebatas untuk kepentingan pembayaran dan pendaftaran pasien. RME dengan CDSS dan prediksi terhadap diagnosis belum pernah ada khususnya di Indonesia. Tujuan penelitian ini adalah mengimplementasikan aplikasi RME di klinik pendidikan dan mengevaluasi kepusan pengguna terhadap aplikasi RME yang diimplementasikan. Metode yang digunakan untuk implementasi RME adalah dengan parallel implementation dan evaluasi kepuasan pengguna dengan metode end user computing satisfaction. Implementasi aplikasi RME dilakukan selama 2 bulan di klinik pendidikan yaitu pada bulan September sampai dengan Oktober 2019. Penelitian melibatkan 2 orang dokter, 1 petugas pendaftaran, 2 perawat dan 1 orang petugas apotek. pada klinik pendidikan. Hasil penelitian aplikasi RME dapat
}

diimplementasikan di klinik pendidikan, aplikasi RME dengan pendukung keputusan klinis berupa penentuan tensi, risiko Diabetes Mellitus, risiko stroke, interaksi konten obat dengan riwayat alergi, serta peringatan tidak normal terhadap hasil pemeriksaan laboratorium dan radiologi.

Keywords-Implementasi; Aplikasi; Rekam Medis Elektonik; klinik Pendidikan

\section{PENDAHULUAN}

Masyarakat memiliki hak untuk mendapatkan pelayanan kesehatan yang bermutu dan terjangkau [1]. Mutu pelayanan kesehatan adalah suatu langkah ke arah peningkatan pelayanan kesehatan baik untuk individu maupun untuk populasi sesuai dengan keluaran (outcome) kesehatan yang diharapkan untuk pengetahuan profesional terkini. Pemberian pelayanan kesehatan harus mencerminkan ketepatan dari penggunaan pengetahuan [2], sehingga pelayanan yang diberikan benar-benar tepat dan dapat menjamin keselamatan pasien.

Penggunaan sumber daya serta aktivitas yang sangat kompleks di rumah sakit atau klinik, berpeluang terjadi kesalahan, seperti kesalahan diagnosis, pemberian resep yang lebih dari standar atau dosis yang berlebihan sehingga berakibat serius atau fatal bagi pasien [3]. Menurut House Of Commons Health Committee Patient Safety Sixth Report of Session 2008-09 Volume I disebutkan bahwa di London $10 \%$ dari pasien yang dirawat di rumah sakit menderita kerusakan yang sangat besar dan ada dari beberapa kerusakan tersebut dapat dihindari, puluhan ribu pasien mengalami kerugian yang sangat besar setiap tahun [4]. Temuan sebelumnya laporan IOM (Institute for Medicine's) yaitu kematian akibat 'Medical error' mencapai 98.000 orang, kerugian antara \$17-29 Juta dan Kontributor terbanyak adalah 'Medical error' [5].

Salah satu upaya untuk mewujudkan pelayanan kesehatan yang bermutu adalah dengan pengelolaan data pasien yang baik, yaitu dengan pemanfaatan teknologi informasi [6] yaitu, fungsi-fungsi pada system informasi diharapkan dapat memfilter terjadinya kesalahan dalam menginput data pasien, serta system pendukung keputusan klinis yang sangat membantu dokter memberikan keputusan medis kepada pasiennya. Urgensi penelitian ini yaitu aplikasi ini berisi menu data anamnesis, hasil pemeriksaan fisik, hasil pemeriksaan laboratorium, hasil pemeriksaan radiologi dengan pendukung keputusan klinis berupa penentuan tensi, risiko Diabetes Mellitus, risiko stroke, interaksi konten obat dengan riwayat alergi, serta peringatan tidak normal terhadap hasil pemeriksaan 
laboratorium dan radiologi. Menu lain yaitu terapi berupa isian data obat dan tindakan medis pasien. Aplikasi ini akan menyimpan riwayat pemeriksaan pasien, sehingga tersedia repository data pasien yang baik, lengkap dan tepat waktu sehingga dapat dengan mudah dipanggil kembali oleh dokter dan dapat mendukung kesalamatan pasien. Tujuan penelitian ini adalah mengimplementasikan aplikasi RME di klinik pendidikan dan mengevaluasi kepusan pengguna terhadap aplikasi RME yang diimplementasikan. Penelitian tentang Penerapan rekam medis elektronik di UPT Poliklinik Politeknik Negeri Jember [7] telah dilakukan pada tahun 2013. Penelitian lain seperti implementasi rekam medis yang terintegrasi [8] serta rekam medis berbasis android juga sudah dilakukan [9]. Namun rekam medis yang ada belum memenuhi fungsi pendukung keputusan klinis untuk pasien-pasien dengan penyakit kronis. Sebagian besar pelayanan kesehatan saat ini menyelenggarakan rekam medis berupa rekam medis kertas sehingga mudah hilang, rusak dan tidak mendukung pengambilan keputusan klinis. Pengembangan RME masih sebatas untuk kepentingan pembayaran dan pendaftaran pasien. RME dengan CDSS dan prediksi terhadap diagnosis belum pernah ada khususnya di Indonesia [10]. Aplikasi RKE dengan pendukung keputusan klinik yang diimplementasikan di klinik pendidikan didalamnya terdapat kolom untuk diisikan hasil yaitu bacaan dokter terhadap data pemeriksaan penunjang, seperti laboratorium dan radiologi, sehingga dengan aplikasi ini dokter terbantu untuk menegakkan diagnosis dari riwayat pasien sebelumnya serta hasil periksaan penunjang.

\section{METODE PENELITIAN}

\section{A. Metode Penelitian}

Metode implementasi aplikasi RME menggunakan metode Parallel implementation, yaitu system baru dalam hal ini RME dengan pendukung keputusan klinis di implementasikan, tetapi system lama yaitu rekam medis kertas, maasih tetap digunakan, sampai klinik benar-benar untuk tidak menggunakan rekam medis kertas sama sekali, atau klinik benar-benar bermigrasi [7].

B. Tempat dan waktu Penelitian

Penelitian berlokasi di klinik pendidikan salah satu perguruan tinggi di Kabupaten Jember. Penelitian dilaksanakan selama 2 bulan yaitu September sampai dengan Oktober 2019.

\section{B. Responden}

Responden adalah dokter penanggung jawab klinik sebanyak 2 orang, 1 petugas pendaftaran, 2 perawat dan 1 orang petugas Apotek.

\section{HASIL DAN PEMBAHASAN}

A. Tahapan implementasi adalah sebagai berikut:

1. Menyiapkan hardware dan jaringan.

Bagian pendaftaran dilengkapi dengan komputer yang telah diinstal aplikasi RME dan printer. Ruang pemeriksaan pasien, apotek, laboratorium dan radiologi juga dilengkapi dengan komputer. RME terintegrasi dari bagian pendaftaran ke bagianbagian yang lainnya. Jaringan atau LAN telah dipersiapkan.

2. Pelatihan penggunaan RME kepada pengguna
Seluruh pengguna diberi pelatihan tentang penggunaan RME agar pengguna terbiasa dan mahir dalam menggubakan RME.

3. Implementasi RME dengan pendukung keputusan klinis.

Implementasi RME dilakukan selama 2 bulan, namun system lama yaitu rekam medis kertas masih tetap digunakan.

4. Evaluasi penggunaan aplikasi RME dengan metode end user computing satisfaction.

Aspek yang dievaluasi meliputi content, accuracy, format, easy of use dan timelines [11].

Hasil evaluasi dari 6 orang responden dipetakan sebagai beriku:

Semua responden sepakat bahwa konten, format, kemudahan dalam menggunakan, serta aplikasi RME benar-benar dapat menyediakan data tepat waktu.

“..........Aplikasi nya mudah digunakan ya
mbak...(Responden 1)”

Namun responden 4 awalnya kesulitan dalam menginputkan data pasien baru.

"Pasien baru itu dientri dimana....? (Responden
4)"
"Wah....aplikasi RME yang ini bisa untuk
memprediksi stroke dan DM juga ya
mbak..(Responden 2)".

B. Berikut adalah desain interface aplikasi RME dengan pendukung keputusan klinis :

1. Pendaftaran pasien

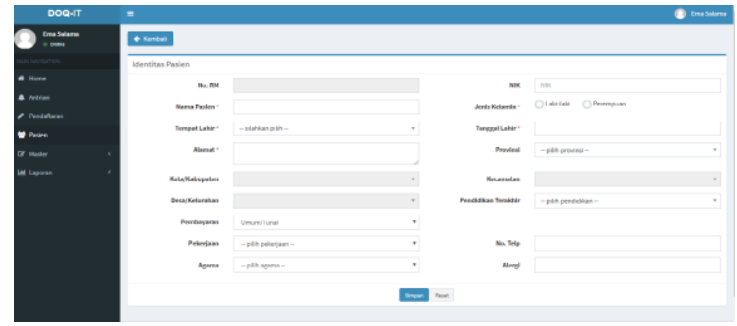

Gambar 1. Pendaftaran Pasien Baru

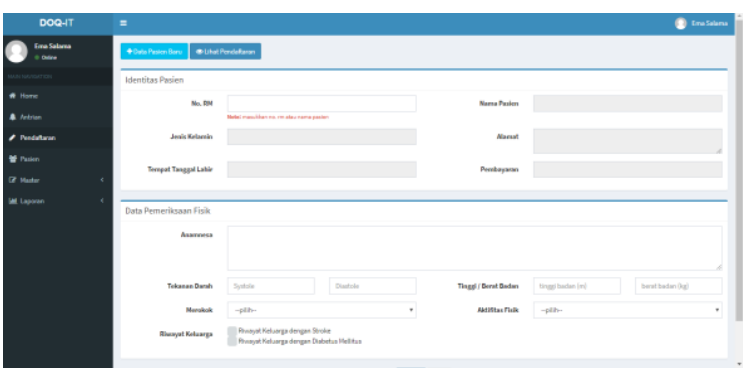

Gambar 2. Pendaftaran Pasien Lama

Pendaftaran dilakukan oleh petugas pendaftaran atau perawat. Data pasien baru akan diinput pada tabel master pasien. Pasien lama cukup menyerahkan KIB (Kartu Indeks Berobat) atau KTP. Petugas pendaftaran juga menginputkan data alergi pasien terhadap salah satu konten obat. Petugas pendaftaran atau perawat juga menginputkan anamnesis, 
pemeriksaan fisik seperti systole, diastole kemudian system secara otomatis memberikan kesimpulan tensi pasien, berupa keterangan normal, hypotensi atau hypertensi. Selain itu petugas pendaftaran juga menginputkan data berat badan dan tinggi badan pasien, kemudian system secara otomatis memberikan kesimpulan status gizi pasien, normal, kurus atau gizi lebih. Pasien juga ditanya tentang riwayat keluarga dengan stroke, Diabetes, kebiasan merokok maupun kebiasaan olah raga. Hal ini untuk memprediksi kemungkinan pasien terdiagnosis stroke dan Diabetes dikemudian hari.
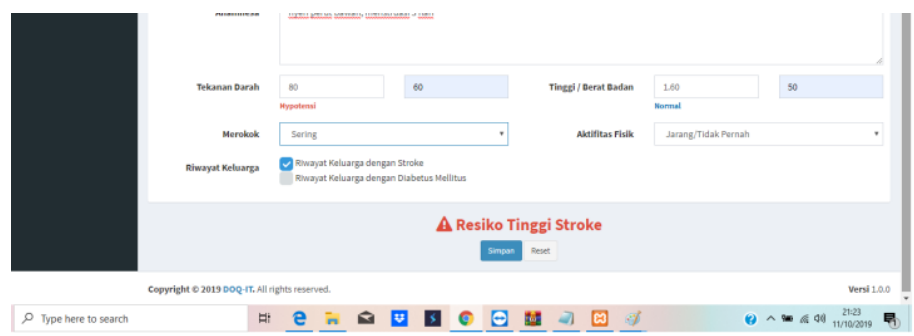

Gambar 3. Pendukung Keputusan Klinis untuk Risiko Stroke

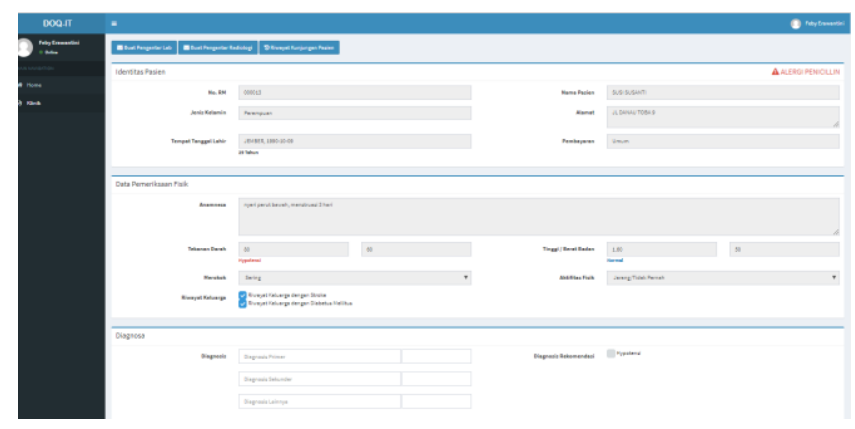

\section{Gambar 4. Menu Pemeriksaan oleh Dokter}

Pada gambar 4. Dapat kita amati menu periksaan oleh dokter. Informasi data sosial, faktor risiko sudah dapat diketahui oleh dokter. Pada menu ini terdapat tabel untuk mengisikan Diagnosis dan terapi, serta perintah dokter untuk pemeriksaan penujang, dalam hal ini laboratorium dan radiologi. hasil pemeriksaan penunjang akan diketahui dokter secara otomatis pada menu ini, karena petugas laboratorium dan radiologi, sebelumnnya telah menginputkan pada sistem insystemi laboratorium dan system informasi radiologi. Apabila terdapat hasil yang menyimpang dari kondisi normal, maka system akan memberikan worning berupa keterangan risiko.

Apabila obat yang diberikan dokter ternyata berisiko menimbulkan reaksi alergi pada pasien, maka system juga akan memberikan worning, sebagai berikut:

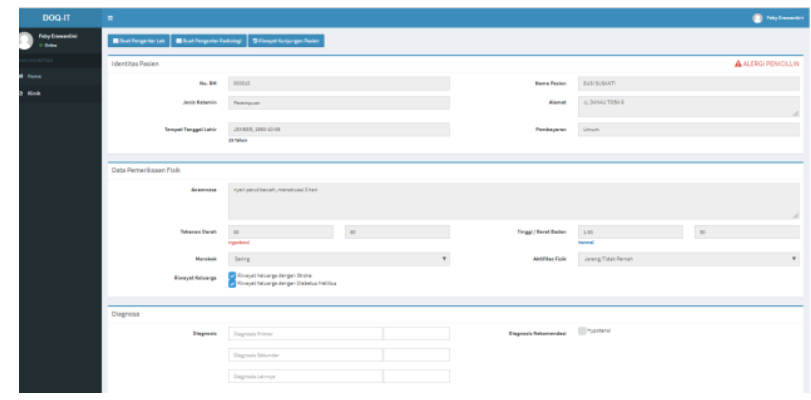

Gambar 5. Pendukung keputusan klinis untuk reaksi alergi obat
Sehingga diharapkan dengan RME tersimpan repository data pasien yang lengkap dan mudah untuk dipanggil kembali, serta mendukung keputusan klinis dan dapat meningkatkan keamanan pasien (patient safety) [12].

\section{Kesimpulan}

1. Implementasi RME dengan pendukung keputusan klinis di Klinik Pendidikan selama 2 bulan dengan tetap menggunakan rekam medis kertas.

2. Hasil evaluasi pengguna terhadap aplikasi RME dengan system pendukung keputusan klinis dapat disimpulkan bahwa pengguna sepakat, konten, format, kemudahan dalam menggunakan, serta aplikasi RME benar-benar dapat menyediakan data tepat waktu. Aplikasi RME dengan pendukung keputusan klinis berupa penentuan tensi, risiko Diabetes Mellitus, risiko stroke, interaksi konten obat dengan riwayat alergi, serta peringatan tidak normal terhadap hasil pemeriksaan laboratorium dan radiologi.

\section{PENGHARGAAN}

Ucapan terima kasih kepada Politeknik Negeri Jember yang telah memberikan sponsor atau support terhadap berlangsungnya penelitian ini.

\section{REFERENSI}

[1] I. Hadiyati, N. Sekarwana, D. K. Sunjaya, and E. P. Setiawati, "Konsep Kualitas Pelayanan Kesehatan berdasar atas Ekspektasi Peserta Jaminan Kesehatan Nasional Health Service Quality Concept based on Expectation of the National Health Insurance Participants," vol. 49, no. 2, 2017.

[2] E. Stefani, "TINJAUAN YURIDIS PELAYANAN KESEHATAN YANG BERMUTU MENURUT PASAL 5 AYAT (2) UNDANGUNDANG NOMOR 36 TAHUN 2009 BERKAITAN DENGAN KEKECEWAAN PASIEN TERHADAP PERILAKU DOKTER," no. 2. Universitas Atma Jaya Yogyakarta, Yogyakarta, pp. 561-565, 2014.

[3] K. T. Kavanagh, D. M. Saman, R. Bartel, and K. Westerman, "Estimating hospital-related deaths due to medical error: A perspective from patient advocates," J. Patient Saf., vol. 13, no. 1, pp. 1-5, 2017.

[4] A. Bari, R. A. Khan, and A. W. Rathore, "Medical errors; causes, consequences, emotional response and resulting behavioral change," Pakistan J. Med. Sci., vol. 32, no. 3, pp. 523-528, 2016.

[5] M. A. W. Khairurrijal and N. A. Putriana, "Review : Medication Erorr Pada Tahap Prescribing, Transcribing, Dispensing, dan Administration," Farmasetika.com (Online), vol. 2, no. 4, p. 8, 2018.

[6] Y. K. Alotaibi and F. Federico, "The impact of health information technology on patient safety," Saudi Med. J., vol. 38, no. 12, pp. 1173-1180, 2017.

[7] F. Erawantini, "Pendahuluan Penggunaan rekam medis elektronik berpotensi memberikan manfaat besar bagi pelayanan kesehatan seperti fasilitas pelayanan dasar maupun rujukan ( rumah sakit). Salah satu manfaat yang dirasakan setalah penggunaan rekam medis elektronik adalah," Fiki, vol. 1, no. 1, pp. 1-10, 2013.

[8] W. Handiwidjojo, "Rekam medis elektronik," Univ. Kristen Duta Wacana Yogyakarta, vol. 2, no. 1, pp. 36-41, 2015.

[9] N. C. Basjaruddin, E. Rakhman, and M. B. Renardi, "Pengembangan Rekam Medis Elektronik Berbasis Near Field Communication ( NFC ) Developing Electronic Medical Record Based on Near Field Communication ( NFC )," Unikom, pp. 53-58, 2018.

[10] D. Cahya and A. Nugraha, "An Overview of e-Health in Indonesia : Past and Present," Int. J. Electr. Comput. Eng., vol. 7, no. 5, pp. 
2441-2450, 2018.

[11] I. Nurjannah and S. Warsini, "Validity and reliability of end-user computing satisfaction in Indonesian language to measure digital nursing assessment tool," AIP Conf. Proc., vol. 1755, no. November, 2016.

[12] C. Tanner, D. Gans, J. White, R. Nath, and J. Pohl, "Electronic health records and patient safety: Co-occurrence of early EHR implementation with patient safety practices in primary care settings," Appl. Clin. Inform., vol. 6, no. 1, pp. 136-147, 2015. 